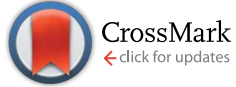

Cite this: RSC Adv., 2017, 7, 8800

Received 5th December 2016 Accepted 22nd January 2017

DOI: 10.1039/c6ra27793d

rsc.li/rsc-advances

\section{Reaction of the hydrogen atom with nitrous oxide in aqueous solution - pulse radiolysis and theoretical study $\uparrow$}

\author{
Lukasz Kazmierczak, Dorota Swiatla-Wojcik* and Marian Wolszczak
}

UB3LYP/cc-pVTZ computations using C-PCM, IEF-PCM, and SMD water-solvent models have been performed for the reaction of the $\mathrm{H}^{\cdot}$ atom with nitrous oxide $\left(\mathrm{N}_{2} \mathrm{O}\right)$ producing $\mathrm{N}_{2}$ and ${ }^{\circ} \mathrm{OH}$ in aqueous solution. The $\mathrm{H}^{\cdot}$ atom attacks the oxygen atom in the $\mathrm{N}_{2} \mathrm{O}$ molecule resulting in the formation of the $[\mathrm{H}-\mathrm{ONN}]^{*}$ transition state and its decomposition into ${ }^{\circ} \mathrm{OH}$ and $\mathrm{N}_{2}$. This direct path requires $54.2 \mathrm{~kJ}$ $\mathrm{mol}^{-1}$ (PCM) or $54.6 \mathrm{~kJ} \mathrm{~mol}^{-1}$ (SMD) compared to $53.0 \mathrm{~kJ} \mathrm{~mol}^{-1}$ in a vacuum. The $\mathrm{H}^{\cdot}$ atom addition to the nitrogen end leads to the $[\mathrm{H}-\mathrm{NNO}]^{\ddagger}$ transition state decaying to a cis-HNNO intermediate that after transformation to $[\mathrm{NNOH}]^{\ddagger}$ finally produces ${ }^{\circ} \mathrm{OH}$ and $\mathrm{N}_{2}$. The total energy expense associated with the indirect mechanism, $67.6 \mathrm{~kJ} \mathrm{~mol}^{-1}$ (PCM) or $65.5 \mathrm{~kJ} \mathrm{~mol}^{-1}(\mathrm{SMD})$, is slightly smaller compared to $67.7 \mathrm{~kJ}$ $\mathrm{mol}^{-1}$ computed for the reaction in vacuum. The temperature dependence of the reaction rate constant obtained based on the pulse radiolysis measurements in $\mathrm{N}_{2} \mathrm{O}$-saturated $0.1 \mathrm{M} \mathrm{HCl}$ solution over the temperature range of $296-346 \mathrm{~K}$ shows the activation energy $(62.6 \pm 2.1)$ or $(59.9 \pm 2.1) \mathrm{kJ} \mathrm{mol}^{-1}$ depending on a form of the pre-exponential factor in the Arrhenius equation, $A$ or $A^{\prime} \times T$, respectively. The activation energy, almost three times higher than observed in gases at temperatures below $500 \mathrm{~K}$, indicates predominance of the direct reaction path via $[\mathrm{H}-\mathrm{ONN}]^{*}$. The indirect mechanism may also contribute, but in contrast to the gas phase reaction neither tunnelling from $[\mathrm{H}-\mathrm{NNO}]^{*}$ to $[\mathrm{NNOH}]^{\star}$ nor collisional stabilization of $[\mathrm{H}-\mathrm{NNO}]^{*}$ occurs in solution.

\section{Introduction}

Rate and mechanism of reactions initiated by $\mathrm{N}_{2} \mathrm{O}$ in aqueous solutions are of growing interests because of the environmental impact of $\mathrm{N}_{2} \mathrm{O}$ and its various applications in chemistry, biology, and medicine. Emissions of $\mathrm{N}_{2} \mathrm{O}$ due to industrial processes and extensive use of fertilizers ${ }^{1}$ contribute either to ozone depletion in the stratosphere ${ }^{2}$ or to the greenhouse effect. ${ }^{3}$ Medicinal, technical and industrial applications of $\mathrm{N}_{2} \mathrm{O}$ result from its anaesthetic and analgesic effects, an inert character and the ability to be a donor of nitrogen and oxygen atoms in chemical reactions. Synthetic chemistry with $\mathrm{N}_{2} \mathrm{O}$ in homogenous solution, ${ }^{4}$ utilization of $\mathrm{N}_{2} \mathrm{O}$ as a whipping agent or fuel additive, ${ }^{5}$ and its role in water remediation by the electron beam treatment ${ }^{6}$ have been recently reviewed. In a class of advanced oxidation processes (AOPs) ionising radiation has been successfully used to generate hydroxyl radicals for degradation of such hazardous pollutants as chlorpyrifos, ${ }^{7}$ 4-chloroaniline ${ }^{8}$ or primidone. ${ }^{9}$ Saturation of water with $\mathrm{N}_{2} \mathrm{O}$ is used to transform the main reducing radiolytic products, hydrated

Institute of Applied Radiation Chemistry, Faculty of Chemistry, Lodz University of Technology, Zeromskiego 116, 90-924 Lodz, Poland.E-mail: swiatlad@p.lodz.pl

$\dagger$ Electronic supplementary information (ESI) available. See DOI: 10.1039/c6ra27793d electrons $\left(\mathrm{e}_{\mathrm{aq}}{ }^{-}\right)$into ${ }^{\circ} \mathrm{OH}$ radicals, thus increasing their concentration in solution.

The reaction of $\mathrm{H}^{\cdot}$ with $\mathrm{N}_{2} \mathrm{O}$ was thoroughly examined in the gas phase in view of its occurrence in combustion chemistry. ${ }^{\mathbf{1 0 - 1 4}}$ Compilation of evaluated kinetic data in the temperature range of $350-2500 \mathrm{~K}$, was provided by Baulch et al. ${ }^{15}$ In contrast to the gas phase, very little is known on the reaction occurring in aqueous solution. The kinetic data on this reaction in solution are available for ambient conditions only, and the reported values of the room temperature rate constant are very divergent, ranging from $1 \times 10^{3}$ to $2 \times 10^{6} \mathrm{M}^{-1} \mathrm{~s}^{-1}$. In our earlier paper a critical test of the room temperature data was carried out. ${ }^{16}$ In a series of pulse radiolysis experiments we traced the decay of dichloride radical ion $\left(\mathrm{Cl}_{2}{ }^{-}\right)$in $\mathrm{N}_{2}$ - and $\mathrm{N}_{2} \mathrm{O}$-saturated $0.1 \mathrm{M} \mathrm{HCl}$ aqueous solution, attributing the slower decay in $\mathrm{N}_{2} \mathrm{O}$-saturated system to the reaction of $\mathrm{H}^{\cdot}$ with $\mathrm{N}_{2} \mathrm{O}$. The obtained room temperature value of the reaction rate constant, $(9 \pm 2) \times 10^{4} \mathrm{M}^{-1} \mathrm{~s}^{-1}$, is about ten times higher than $k_{\mathrm{g}}=6.2 \times 10^{3} \mathrm{M}^{-1} \mathrm{~s}^{-1}$ calculated from eqn (1), which is recommended for the gas phase reaction. ${ }^{15}$

$$
\begin{aligned}
k_{\mathrm{g}}\left[\mathrm{M}^{-1} \mathrm{~s}^{-1}\right]=3.31 & \times 10^{7} \exp (-2560 / T)+7.83 \\
& \times 10^{11} \exp (-9750 / T)
\end{aligned}
$$

The quantum chemical computations of the reaction in vacuum shows two reaction paths ${ }^{13}$ described by eqn (2) and (3). 
Path (2) refers to the $\mathrm{H}^{\bullet}$ atom attack on the oxygen atom in the $\mathrm{N}_{2} \mathrm{O}$ molecule and leads to the formation of the $[\mathrm{H}-\mathrm{ONN}]^{\ddagger}$ transition state decomposing into ${ }^{\circ} \mathrm{OH}$ and $\mathrm{N}_{2}$.

$$
\mathrm{H}^{\cdot}+\mathrm{N}_{2} \mathrm{O} \rightarrow[\mathrm{H}-\mathrm{ONN}]^{*} \rightarrow \cdot \mathrm{OH}+\mathrm{N}_{2}
$$

Path (3) corresponds to the $\mathrm{H}^{*}$ atom addition to the nitrogen end to form $[\mathrm{H}-\mathrm{NNO}]^{\ddagger}$ and then cis-HNNO, which may either isomerise to stable trans-HNNO, or produce $\mathrm{N}_{2}$ and ${ }^{\circ} \mathrm{OH}$ via the $[\mathrm{NNOH}]^{*}$ transition state.

$$
\begin{aligned}
& \mathrm{H}^{\cdot}+\mathrm{N}_{2} \mathrm{O} \rightarrow[\mathrm{H}-\mathrm{NNO}]^{*} \rightarrow \text { cis } \mathrm{HNNO} \rightarrow \\
& \left\{\begin{array}{c}
{[\mathrm{NNOH}]^{*} \rightarrow \cdot \mathrm{OH}+\mathrm{N}_{2}} \\
\text { cis } / \text { trans }[\mathrm{HNNO}]^{*} \rightarrow \text { trans } \mathrm{HNNO}
\end{array}\right.
\end{aligned}
$$

Given the above the following questions arise: (i) what is the temperature dependence of the reaction rate constant in solution and (ii) what is the solvent effect on the reaction mechanism. To the best of our knowledge these problems have never been discussed. With the aim to fill this gap, our kinetic measurements have been extended here up to $346 \mathrm{~K}$ and combined with quantum chemical calculations carried out for the reaction in vacuum and in solution. The experimental procedure is presented in Sec. 2 and processing of the acquired kinetic data is described in Sec. 3. The DFT computations at the UB3LYP/cc-pVTZ level of theory assuming C-PCM, IEF-PCM, and SMD solvent models are described in Sec. 4, and the solvent effect on the reaction kinetics and mechanism is discussed in Sec. 5. The summary and conclusions are given in Sec. 6 .

\section{Pulse radiolysis measurements}

Pulse radiolysis measurements were carried out using the same experimental setup as before. ${ }^{\mathbf{1 6}}$ The duration of electron beam pulses delivered from the $6 \mathrm{MeV}$ ELU-6 linear accelerator was 7 or $17 \mathrm{~ns}$, giving the dose of $(14.0 \pm 0.4)$ Gy or $(46.5 \pm 1.4)$ Gy respectively, as evaluated using $\mathrm{N}_{2} \mathrm{O}$-saturated $0.01 \mathrm{M}$ solution of potassium thiocyanate (KSCN) as the dosimeter and taking $\mathrm{G} \varepsilon_{475}=5.28 \times 10^{-4} \mathrm{~m}^{2} \mathrm{~J}^{-1} \cdot{ }^{17}$ The stock $0.1 \mathrm{M} \mathrm{HCl}$ aqueous solutions were deoxygenated by purging with high purity $\mathrm{N}_{2} \mathrm{O}$ and then irradiated. In this system the hydroxyl radical is rapidly converted to $\mathrm{Cl}_{2}{ }^{\cdot-} \cdot{ }^{18}$ Comparative measurements have been also carried out for $\mathrm{N}_{2}$-saturated solutions. The decay of $\mathrm{Cl}_{2}{ }^{--}$absorbance was traced over the temperature range of 296$346 \mathrm{~K}$ at $340 \mathrm{~nm}$ being the absorption maximum of $\mathrm{Cl}_{2}{ }^{--}$. The molar absorption coefficient $\varepsilon_{340}=960 \mathrm{~m}^{2} \mathrm{~mol}^{-1}$ (ref. 19) was assumed for all temperatures. The optical absorption was recorded using a monochromator ARC SpectraPro275, a photomultiplier R 928 Hamamatsu Photonics and an oscilloscope Tektronix TDS $500 \mathrm{MHz}$. The optical path of the cell was $1 \mathrm{~cm}$.

\section{Kinetic data processing}

\section{Diffusion-kinetic modelling of spur chemistry}

The ionization of aqueous solutions by high energy electrons results in the ultrafast formation of highly reactive hydrated electrons $\left(\mathrm{e}_{\mathrm{aq}}{ }^{-}\right)$and ${ }^{\circ} \mathrm{OH}$ radicals, which are non- homogeneously distributed in isolated spherical spurs formed along the radiation track. We simulate evolution of the radiolytic species during the spur expansion in $\mathrm{N}_{2} \mathrm{O}$ saturated aqueous solution of $0.1 \mathrm{M} \mathrm{HCl}$ using the extended diffusionkinetic approach, ${ }^{20}$ successfully adopted to reproduce the $\mathrm{pH}$ effect on spur chemistry in irradiated aqueous solutions. ${ }^{21}$ The computations have been based on the numerical algorithm, developed by Burns et al. ${ }^{22}$ which divides the reaction space into a number of concentric zones and treats reactions in each zone and simultaneous mass flow between adjoining zones according to the Fick's law of diffusion. The reactants were placed into each zone according to the initial Gaussian distributions. Following the extended diffusion-kinetic model the initial species distributions have been described by the properly chosen set of parameters accounting for the early track events, occurring within $\mathrm{ca} \cdot 10^{-12} \mathrm{~s}$. The parameters and the reaction scheme assumed to simulate evolution of the average radiation spur in $\mathrm{N}_{2} \mathrm{O}$ saturated $0.1 \mathrm{M} \mathrm{HCl}$ solution are given in ESI. $\uparrow$ A set of coupled differential equations describing, the mutual second order reactions of the transient species, the first order reactions with the dissolved scavengers $\left(\mathrm{N}_{2} \mathrm{O}\right.$, hydronium and chloride ions), and simultaneous diffusion of the radiolytic species has been solved numerically using FACSIMILE 4 software package. Simulation has been also carried out for $\mathrm{N}_{2}$-saturated $0.1 \mathrm{M} \mathrm{HCl}$ solution. A temporal evolution of the main radiolytic species is presented in Fig. 1. Solid and dashed lines refer to $\mathrm{N}_{2} \mathrm{O}$ - and $\mathrm{N}_{2}$ saturated solution, respectively. Numerical integration of the diffusion-kinetic equations up to the time limit of $0.1 \mu \mathrm{s}$, corresponding to decay of spatial correlations, provides the $G$ values or the primary yields. In $\mathrm{N}_{2} \mathrm{O}$-saturated solution scavenging of the hydrated electron by $\mathrm{N}_{2} \mathrm{O}$ in reaction (4), competes with the $\mathrm{H}^{\cdot}$ atom formation in the reaction with the $\mathrm{H}_{3} \mathrm{O}^{+}$ion. At ambient temperature about $13 \%$ of $\mathrm{e}_{\mathrm{aq}}{ }^{-}$is scavenged by $\mathrm{N}_{2} \mathrm{O}$, resulting in a partial restoration of ${ }^{\circ} \mathrm{OH}$ and in a lower primary yield of the $\mathrm{H}^{*}$ atom.

$$
\mathrm{e}_{\mathrm{aq}}{ }^{-}+\mathrm{N}_{2} \mathrm{O} \rightarrow \mathrm{O}^{-}+\mathrm{N}_{2} \stackrel{+\mathrm{H}_{2} \mathrm{O}}{\longrightarrow} \cdot \mathrm{OH}+\mathrm{OH}^{-}+\mathrm{N}_{2}
$$

Within $c a .70$ ns the hydroxyl radical is converted to $\mathrm{Cl}_{2}{ }^{\cdot-}$ via complex reaction (R6) given in Table 2. Therefore, in $\mathrm{N}_{2} \mathrm{O}$ saturated system reaction (4) contributes to the higher yield of $\mathrm{Cl}_{2}{ }^{--}$.

The primary yields of the radical and molecular products computed for the high energy electron radiolysis of $\mathrm{N}_{2} \mathrm{O}$ saturated solution at different temperatures are given in Table 1. A small amount of $\mathrm{H}_{2} \mathrm{O}_{2}$ results from the recombination of 'OH radicals prior to the scavenging by $\mathrm{Cl}^{-}$anions. The temperature dependence for the rate of reaction (R6) in Table 2 has been modelled as diffusion controlled because in $0.1 \mathrm{M} \mathrm{HCl}$ solution all the equilibria are shifted to the right. The calculated $G$-values showed low sensitivity either to the value of the activation energy assumed for the overall rate of reaction (R6) or to the examined temperature dependence for the reaction rate constant of the title reaction, denoted as R1 in Table 2.

$\ddagger$ Facsimile 4 for Windows, MCPA software, version 4.2.50. 

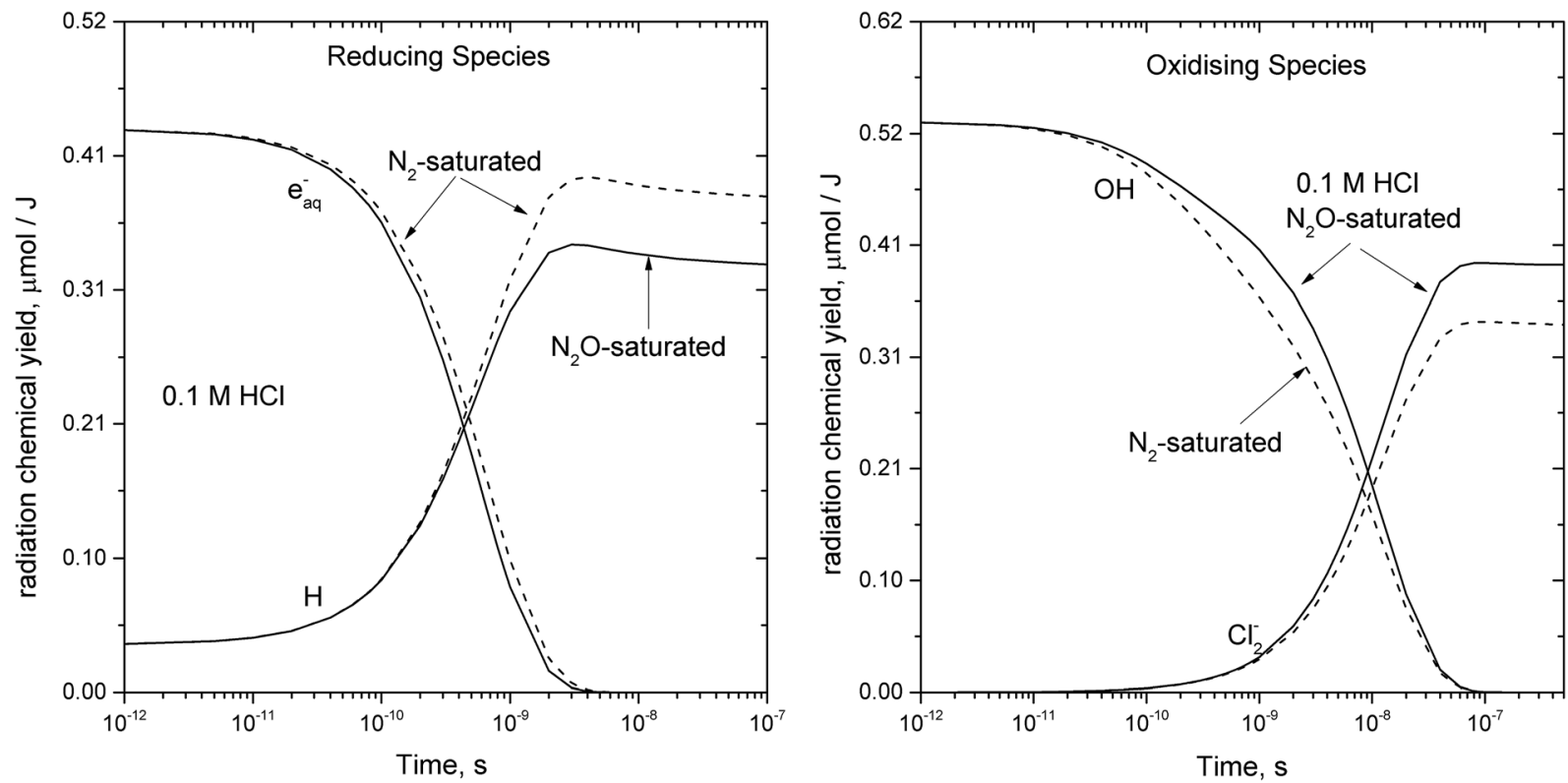

Fig. 1 Simulated evolution of the average radiation spur in $0.1 \mathrm{M} \mathrm{HCl}$ aqueous solution at ambient temperature: solid - $\mathrm{N}_{2} \mathrm{O}$-saturated and dash - $\mathrm{N}_{2}$-saturated system.

Table 1 The radiation chemical yields of radical and molecular products computed for $\mathrm{N}_{2} \mathrm{O}$ saturated $0.1 \mathrm{M} \mathrm{HCl}$ aqueous solution at different temperatures. ${ }^{a}$ The $G$-values are expressed in $\mu \mathrm{mol} \mathrm{J}^{-1}$

\begin{tabular}{lllll}
\hline$T(\mathrm{~K})$ & $G\left(\mathrm{H}^{\cdot}\right)$ & $G\left(\mathrm{Cl}_{2}{ }^{\cdot-}\right)$ & $G\left(\mathrm{H}_{2} \mathrm{O}_{2}\right)$ & $G\left(\mathrm{H}_{2}\right)$ \\
\hline 298 & 0.331 & 0.398 & 0.064 & 0.042 \\
313 & 0.346 & 0.406 & 0.056 & 0.042 \\
333 & 0.371 & 0.409 & 0.052 & 0.044 \\
353 & 0.393 & 0.408 & 0.047 & 0.046
\end{tabular}

${ }^{a}$ Details on the temperature dependence for the reaction rate constants and model parameters are given in ESI. The temperature dependence for reaction of $\mathrm{e}_{\mathrm{aq}}{ }^{-}$with $\mathrm{N}_{2} \mathrm{O}$ was taken from ref. 40 .

\section{Fitting of kinetic traces}

The concentration profiles of $\mathrm{Cl}_{2}{ }^{-}-$recorded in pulse radiolysis experiments have been fitted using FACSIMILE software. As seen from Table 1 the main transient species produced by high energy electron radiolysis in our systems are $\mathrm{Cl}_{2}{ }^{-}$and $\mathrm{H}^{*}$. The amount of $\mathrm{H}_{2} \mathrm{O}_{2}$ is too small to contribute to the decay of $\mathrm{Cl}_{2}{ }^{-}$. Therefore, a set of differential kinetic equations has been limited to the reactions listed in Table 2.

The primary yields $G\left(\mathrm{Cl}_{2}{ }^{-}\right)$and $G\left(\mathrm{H}^{*}\right)$ resulting from the diffusion-kinetic modelling have been used to estimate the initial concentration of hydrogen atom $c_{\mathrm{H}}(0)$ from the following formula:

$$
c_{\mathrm{H}}(0)=c_{\mathrm{Cl}_{2} \cdot{ }^{--}}^{\mathrm{obs}}(0) \times \frac{G\left(\mathrm{H}^{\cdot}\right)}{G\left(\mathrm{Cl}_{2}{ }^{\cdot-}\right)}
$$

where $c_{\mathrm{Cl}_{2}{ }^{-}}^{\mathrm{obs}}(0)$ has been obtained from the maximum absorbance at a given temperature.

The fitted first order rate constant, $k_{\mathrm{R} 1}^{\prime}$, depends on the concentration of dissolved $\mathrm{N}_{2} \mathrm{O}, c_{\mathrm{N}_{2} \mathrm{O}}$. Since in our system $c_{\mathrm{N}_{2} \mathrm{O}}$ decreases with the increasing temperature, the second order rate constant, $k_{\mathrm{R} 1}$, has been calculated using eqn (6):

Table 2 Set of reactions assumed in the fitting procedure of the kinetic traces of $\mathrm{Cl}_{2}{ }^{-}$decay in $\mathrm{N}_{2} \mathrm{O}$-saturated $0.1 \mathrm{M} \mathrm{HCl}$ solution. The recommended room temperature rate constant, $k_{25}$, and the reference to the temperature dependence for the reaction rate are also given

\begin{tabular}{|c|c|c|c|}
\hline No. & Reaction & $k_{25}, \mathrm{M}^{-1} \mathrm{~s}^{-1}$ & Ref. \\
\hline R1 & $\mathrm{H}^{\cdot}+\mathrm{N}_{2} \mathrm{O} \rightarrow{ }^{\cdot} \mathrm{OH}+\mathrm{N}_{2}$ & $(9 \pm 2) \times 10^{4}$ & This work \\
\hline $\mathrm{R} 2$ & $\mathrm{H}^{\cdot}+\mathrm{H}^{\cdot} \rightarrow \mathrm{H}_{2}$ & $(5.6 \pm 1.3) \times 10^{9}$ & 41 \\
\hline R4 & $\mathrm{Cl}_{2}^{\cdot-}+\mathrm{Cl}_{2}^{\cdot-} \rightarrow \mathrm{Cl}_{2}+2 \mathrm{Cl}^{-}$ & $(1.27 \pm 0.13) \times 10^{9 a}$ & 42 \\
\hline R5 & $\mathrm{H}^{\cdot}+\mathrm{Cl}_{2} \rightarrow \mathrm{H}^{+}+\mathrm{Cl}_{2}^{\cdot-}$ & $(7.6 \pm 1.9) \times 10^{9}$ & 18 \\
\hline R6 & $\cdot \mathrm{OH} \stackrel{+\mathrm{Cl}^{-}}{\longleftrightarrow} \mathrm{HOCl}^{\cdot-} \stackrel{+\mathrm{H}^{+}}{\longleftrightarrow} \mathrm{Cl}^{\cdot}+\mathrm{H}_{2} \mathrm{O} \stackrel{+\mathrm{Cl}^{-}}{\longleftrightarrow} \mathrm{Cl}_{2}{ }^{\cdot}-$ & $7.4 \times 10^{7} \mathrm{~s}^{-1 b}$ & $c$ \\
\hline
\end{tabular}

${ }^{a}$ Calculated for the ionic strength of $0.1 \mathrm{M}^{b}$ See ref. $18 .{ }^{c}$ Calculated assuming the rate determining diffusional encounter of ${ }^{\circ} \mathrm{OH}$ and $\mathrm{Cl}^{-}$and the activation energy of $18 \mathrm{~kJ} \mathrm{~mol}^{-1}$. 


$$
k_{\mathrm{R} 1}(T)=\frac{k_{\mathrm{R} 1}^{\prime}(T)}{c_{\mathrm{N}_{2} \mathrm{O}}(T)}=\frac{k_{\mathrm{R} 1}^{\prime}(T)}{K_{\mathrm{H}}^{\mathrm{N}_{2} \mathrm{O}}(T) \times\left[1 \mathrm{~atm}-P_{\mathrm{H}_{2} \mathrm{O}}(T)\right]}
$$

where the temperature dependences for the Henry's constant, $K_{\mathrm{H}}^{\mathrm{N}_{2} \mathrm{O}}$, and the pressure of saturated water vapour, $P_{\mathrm{H}_{2} \mathrm{O}}$ were respectively taken from ref. 23 and 24 .

\section{DFT computations and results}

The reaction of the $\mathrm{H}^{\cdot}$ atom with $\mathrm{N}_{2} \mathrm{O}$ has been modelled in vacuum and in aqueous solution. Although the potential energy surface of the reaction $\mathrm{H}^{\cdot}+\mathrm{N}_{2} \mathrm{O}$ in the gas phase was computed previously by various methods, ${ }^{13,25-30}$ to the best of our knowledge the reaction path in aqueous solution is studied here for the first time. The density functional theory (DFT) calculation have been performed using GAUSSIAN 09W. ${ }^{31}$ The unrestricted hybrid three-parameter functional UB3LYP including the Becke 88 exchange functional, the correlation functional of Lee, Yang and Parr, and the Dunning's correlation-consistent triple-zeta basis set cc-pVTZ ${ }^{32}$ have been chosen. The calculation procedure started with the optimization of stationary points geometries. The self-consistent field (SCF) procedure has been controlled by the quadratically convergent method, involving linear searches when far from convergence, and NewtonRaphson steps otherwise. After the optimization, the force constants and the resulting vibrational frequencies have been computed to specify the thermodynamic output. Geometries and vibrational frequencies of the stationary points are given in ESI. $\dagger$ The energies have been corrected to zero-point energy (ZPE). In Table 3 the energies obtained for the reaction in vacuum are presented along with the literature reports from previous computational studies. Our UB3LYP results agree with the B3LYP energy values. Both approaches use the spinunrestricted formalism for open shelled structures, which assigns different spatial orbitals to the $\alpha$ and $\beta$ electrons of unlike spin. A slight difference in the $[\mathrm{H}-\mathrm{NNO}]^{+}$and $[\mathrm{NNOH}]^{+}$ energies is possibly due to the use of spin-unrestricted functional in our UB3LYP calculations for all the structures, and the spin-restricted functional set as default for the closed shelled $\mathrm{N}_{2} \mathrm{O}$ molecule in B3LYP calculations. In comparison with more accurate methods, the $[\mathrm{H}-\mathrm{NNO}]^{*}$ and $[\mathrm{H}-\mathrm{ONN}]^{*}$ energies predicted by UB3LYP or B3LYP computations are lower. However, according to all the methods the $[\mathrm{H}-\mathrm{ONN}]^{*}$ transition state energy is about two times higher than the $[\mathrm{H}-\mathrm{NNO}]^{*}$ one. It is consistent with the quasi-classical trajectory calculations indicating that the trajectories associated with the direct path via the $\mathrm{H}^{*}$ atom attack on the oxygen atom and the formation of the $[\mathrm{H}-\mathrm{ONN}]^{*}$ transition state has shorter collision times than those corresponding to the $\mathrm{H}^{*}$ atom attachment to the nitrogen end of the $\mathrm{N}_{2} \mathrm{O}$ molecule. ${ }^{26}$

The UB3LYP/cc-pVTZ computations of the reaction path in water have been carried out assuming two values of the dielectric constant $\varepsilon=78.355$ and $\varepsilon=63.677$, corresponding to the solvent at 298 and $343 \mathrm{~K}$, respectively. We employed two polarizable continuum models (PCMs), C-PCM and IEF-PCM, and SMD model. ${ }^{33}$ The IEF-PCM self-consistent reaction field method uses the integral equation formalism variant ${ }^{34}$ and the conductor-like solvation C-PCM model. ${ }^{35}$ In the SMD approach the free energy of solvation is separated into the bulk electrostatic component and the short-range interaction energy between a solute and solvent molecules in the first solvation shell. Calculation of the long-range electrostatic component is based on the solution of the Poisson equation in terms of the IEF-PCM method. The short-range component includes dispersion energies and a cavitation energy associated with the formation of a cavity in the liquid solvent.

Fig. 2 shows the intrinsic reaction coordinate (IRC) diagram computed for the reaction $\mathrm{H}^{*}+\mathrm{N}_{2} \mathrm{O}$ in vacuum and in solution. Part (a) shows the reaction path resulting from the $\mathrm{H}^{\cdot}$ atom attack on the nitrogen end of the $\mathrm{N}_{2} \mathrm{O}$ molecule, whereas part (b) refers to the attack on the oxygen atom. The attack on the $\mathrm{N}$ atom leads to the $[\mathrm{H}-\mathrm{NNO}]^{+}$transition state followed by the formation of cis-HNNO intermediate, which may either isomerise to trans-HNNO or transform to the $[\mathrm{NNOH}]^{*}$ intermediate decomposing into ${ }^{\circ} \mathrm{OH}$ and $\mathrm{N}_{2}$. The attack on the $\mathrm{O}$ atom leads to the formation of the $[\mathrm{H}-\mathrm{ONN}]^{\star}$ transition state directly decomposing to the products. The energies of the stationary points in solution are presented in Table 4 along with the UB3LYP results obtained for vacuum. Geometries and vibrational frequencies of the stationary points in solution are given in ESI. $\dagger$ Within the considered range of temperature, all the solvent models are insensitive to the value of $\varepsilon$. Compared to vacuum, the PCM models show slightly higher energy barriers for $[\mathrm{H}-\mathrm{ONN}]^{\ddagger}$ and $[\mathrm{NNOH}]^{\ddagger}$, but clearly lower energy levels of $\mathrm{cis} /$ trans $[\mathrm{HNNO}]^{*}$, cis-HNNO, trans-HNNO, and $\mathrm{N}_{2}+\mathrm{OH}$, all calculated relative to the energy level of the reactants. The SMD

Table 3 The computed energies of the stationary points of the potential energy surface of the $\mathrm{H}^{*}+\mathrm{N}_{2} \mathrm{O}$ reaction in vacuum in comparison with other computational studies. The energies are given in $\mathrm{eV}$

\begin{tabular}{|c|c|c|c|c|c|c|c|c|c|c|}
\hline Species & $\begin{array}{l}\text { QCISD }(T) \\
\text { cc-pVTZ }\end{array}$ & $\begin{array}{l}\operatorname{CCSD}(\mathrm{T}) \\
\operatorname{CBS}\{\mathrm{Q}, 5\}\end{array}$ & $\begin{array}{l}\text { CASSCF/ICCI } \\
\text { cc-pVTZ }\end{array}$ & G3X & G2 & $\begin{array}{l}\text { B3LYP } \\
\text { cc-pVTZ }\end{array}$ & G2//QCISD & BAC MP4 & $\begin{array}{l}\text { MRD-CI//HF } \\
4-31 G(d, p)\end{array}$ & $\begin{array}{l}\text { UB3LYP } \\
\text { cc-pVTZ }\end{array}$ \\
\hline$[\mathrm{H}-\mathrm{ONN}]^{+}$ & 0.84 & & 0.78 & & 0.69 & 0.55 & & 0.86 & & 0.55 \\
\hline$[\mathrm{H}-\mathrm{NNO}]^{\ddagger}$ & 0.49 & 0.31 & 0.45 & 0.42 & 0.40 & 0.25 & 0.40 & 0.16 & 0.82 & 0.24 \\
\hline cis-HNNO & -0.59 & -0.75 & -0.63 & -0.51 & -0.67 & -0.88 & -0.62 & -0.63 & -1.27 & -0.88 \\
\hline $\begin{array}{l}{[\mathrm{NNOH}]^{\ddagger}} \\
\text { cis/trans-[HNNO }]^{*}\end{array}$ & 0.72 & 0.75 & 0.71 & 0.83 & 0.81 & $\begin{array}{l}0.71 \\
-0.13\end{array}$ & $\begin{array}{l}0.72 \\
-0.16\end{array}$ & 0.72 & $\begin{array}{l}0.99 \\
-0.095\end{array}$ & $\begin{array}{l}0.70 \\
-0.13\end{array}$ \\
\hline trans-HNNO & -0.84 & -1.00 & -0.86 & -0.90 & -0.93 & -1.12 & -0.93 & -0.93 & -1.28 & -1.12 \\
\hline $\mathrm{N}_{2}+\mathrm{OH}$ & -2.73 & -2.77 & & -2.72 & -2.71 & -2.56 & -2.71 & -2.87 & -2.67 & -2.51 \\
\hline Ref. & 26 & 27 & 28 & 28 & 26 & 25 & 29 & 13 & 30 & (This work) \\
\hline
\end{tabular}




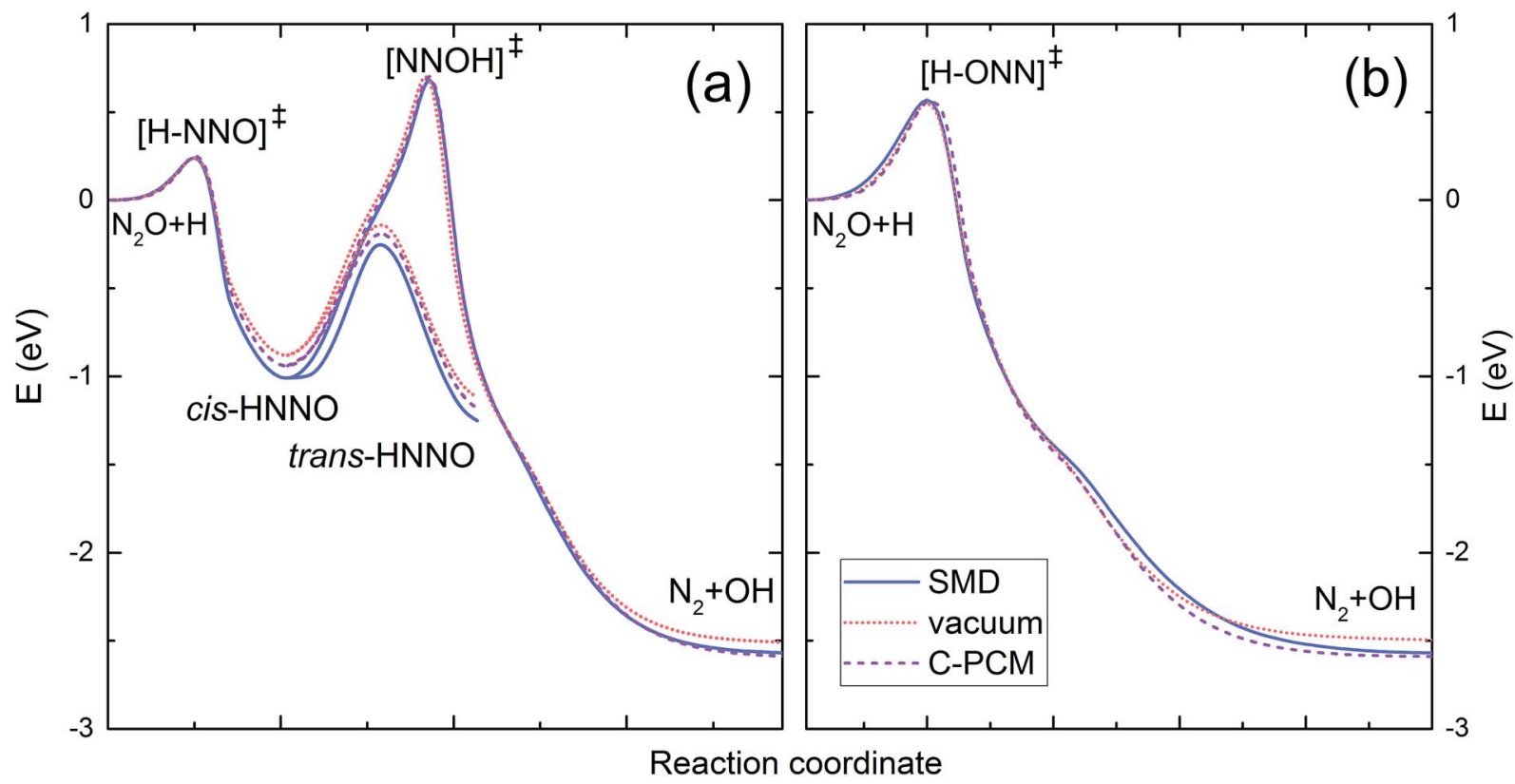

Fig. 2 Rescaled intrinsic reaction coordinate (IRC) plot for the reaction of the $\mathrm{H}^{*}$ atom with $\mathrm{N}_{2} \mathrm{O}$ derived from the potential energy surface calculation with the UB3LYP/cc-pVTZ method in vacuum (dotted line) and in solution using the SMD model (solid line) and C-PCM (dashed line): (a) the $\mathrm{H}^{*}$ atom attack on the nitrogen end of the $\mathrm{N}_{2} \mathrm{O}$ molecule; (b) the $\mathrm{H}^{*}$ atom attack on the oxygen atom.

Table 4 The UB3LYP/cc-pVTZ energies ${ }^{a}$ of the stationary points obtained in this work for the $\mathrm{H}^{*}+\mathrm{N}_{2} \mathrm{O}$ reaction in vacuum and in solution using C-PCM, IEF-PCM, and SMD water-solvent models and assuming two values of the dielectric constant $\varepsilon$

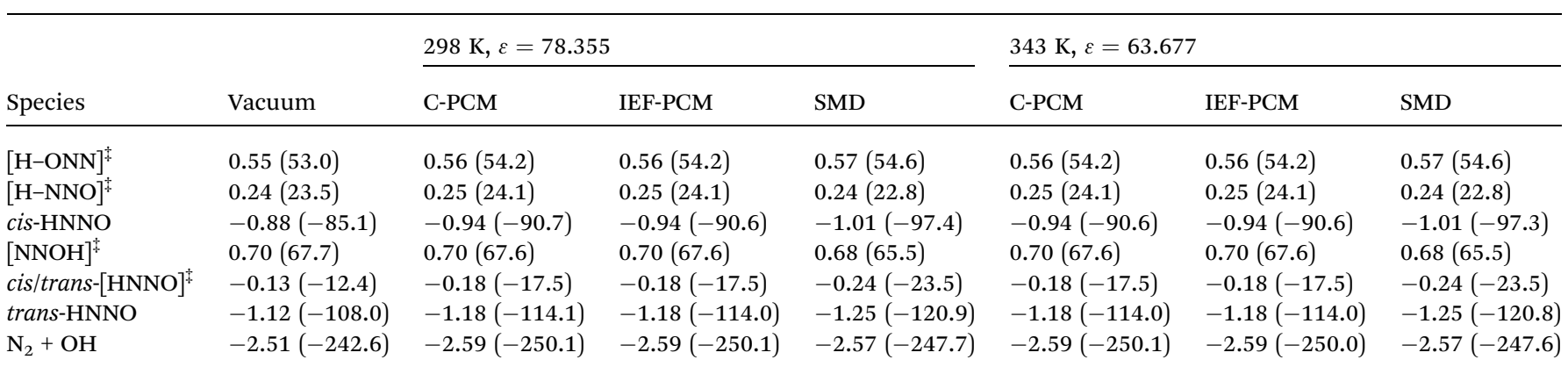

${ }^{a}$ The energies expressed in eV include ZPE correction. The values in $\mathrm{kJ} \mathrm{mol}^{-1}$ are given in parentheses.

model predicts better stabilization of cis/trans[HNNO $]^{*}$, cisHNNO, trans-HNNO, a slightly higher energy barrier for $[\mathrm{H}-$ $\mathrm{ONN}]^{\ddagger}$, but a lower one for the $[\mathrm{NNOH}]^{*}$ transition state. Unlike the PCM models, the SMD energy barrier for the formation of $[\mathrm{NNOH}]^{+}$is slightly below that in vacuum.

\section{Discussion}

The reaction in solution - pulse radiolysis results

Fig. 3 presents selected absorption traces of $\mathrm{Cl}_{2}{ }^{--}$decay in $\mathrm{N}_{2} \mathrm{O}$ and $\mathrm{N}_{2}$-saturated $0.1 \mathrm{M} \mathrm{HCl}$ solution. The FACSIMILE fits obtained taking into account the reaction set from Table 2 and allowing the first order rate constant $k_{\mathrm{R} 1}^{\prime}$ to vary are shown in Fig. 3 by solid lines through the experimental traces. The decay of $\mathrm{Cl}_{2}{ }^{-}$in $\mathrm{N}_{2} \mathrm{O}$-saturated solution is significantly slower. Numerical simulation shows that in $\mathrm{N}_{2} \mathrm{O}$-saturated solution contribution of reaction (R3) to the decay of $\mathrm{Cl}_{2}{ }^{--}$is more limited because the $\mathrm{H}^{*}$ atom is partially consumed in reaction with $\mathrm{N}_{2} \mathrm{O}$. The role of reaction (R1) is confirmed by more striking slow-down of the $\mathrm{Cl}_{2}{ }^{-}$- decay observed in $7 \mathrm{~ns}$ pulse (lower dose) experiments. A noticeable difference between the kinetic traces shown for 313 and $343 \mathrm{~K}$ indicates that the significance of the reaction $\mathrm{H}^{\cdot}+\mathrm{N}_{2} \mathrm{O}$ rapidly increases with temperature.

Fig. 4 shows the Arrhenius plot of the rate constant of reaction (R1) calculated based on the fitted rate constants $k_{\mathrm{R} 1}^{\prime}$ and eqn (6). The error bars include uncertainty in both the fitted values of $k_{\mathrm{R} 1}^{\prime}$ and in $\mathrm{N}_{2} \mathrm{O}$-concentration. The latter has been estimated to be $\pm 10 \%$ at each temperature. The activation energy $E_{\mathrm{a}}=(62.6 \pm 2.1) \mathrm{kJ} \mathrm{mol}^{-1}$ has been obtained from a weighted nonlinear regression using the Marquardt-Levenberg method and OriginPro 2016 software. Inset in Fig. 4 


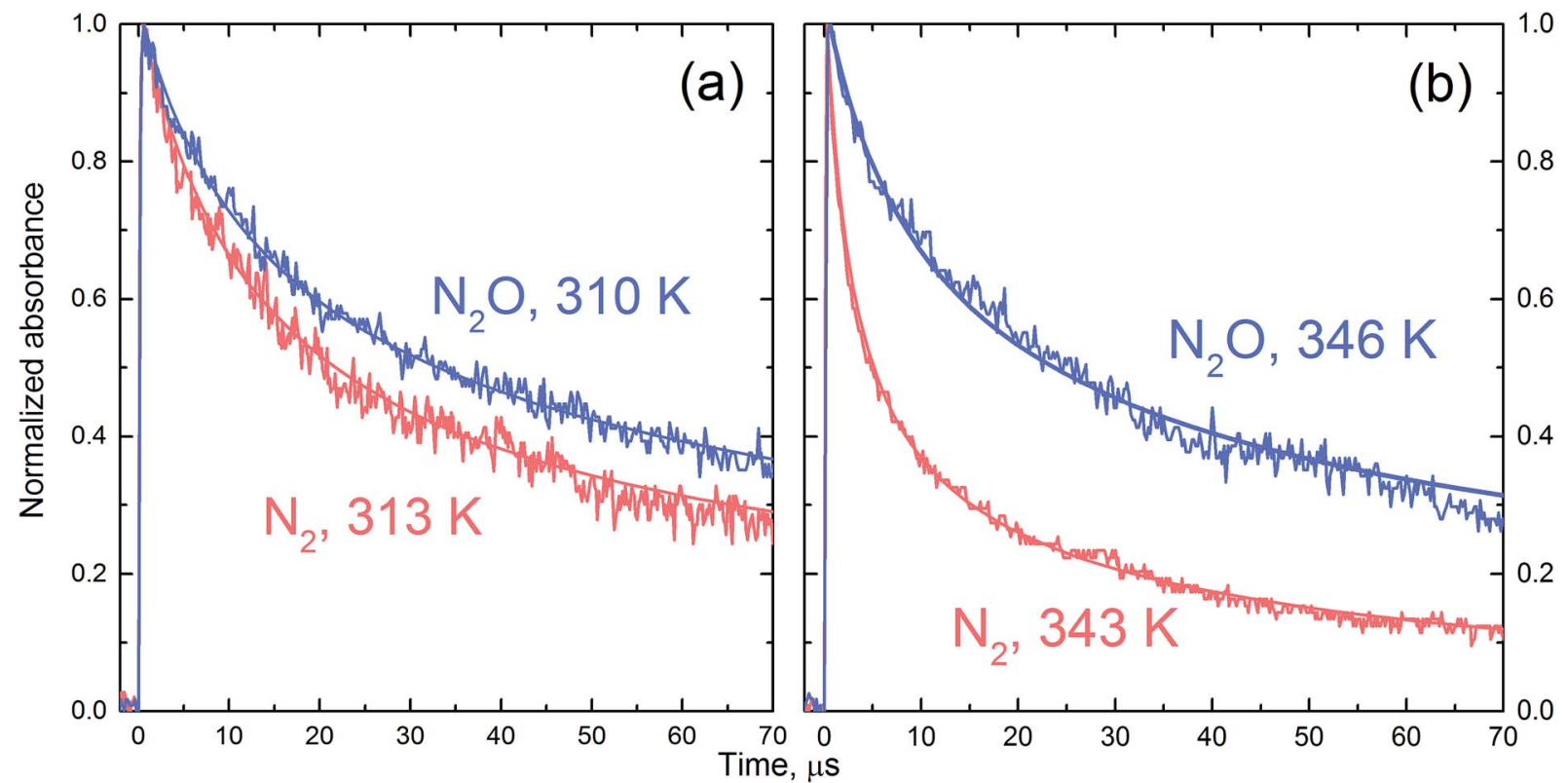

Fig. 3 The normalized-to-maximum transient absorbance of $\mathrm{Cl}_{2}{ }^{\cdot-}$ in pulse irradiated aqueous $0.1 \mathrm{HCl}$ solution saturated with $\mathrm{N}_{2}$ (pink) and $\mathrm{N}_{2} \mathrm{O}$ (blue) recorded at $340 \mathrm{~nm}$ after $7 \mathrm{~ns}$ pulse at ca. $313 \mathrm{~K}$ (a) and $343 \mathrm{~K}$ (b). The solid lines through the experimental traces present FACSIMILE fits obtained taking into account the reaction set from Table 2 , and allowing $k_{\mathrm{R} 1}^{\prime}$ to vary.

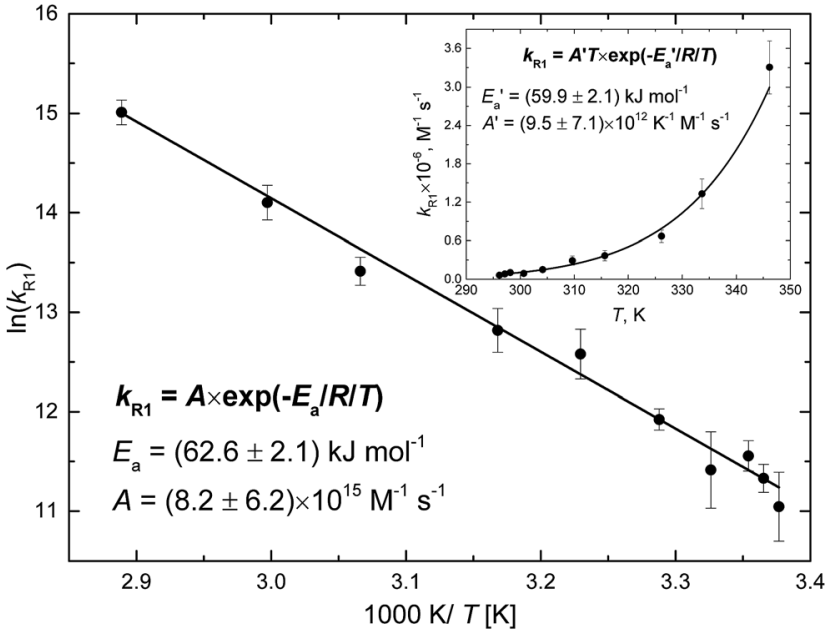

Fig. 4 The measured rate constant of reaction (R1) as a function of temperature (points). The error bars include uncertainty in both $k^{\prime}{ }_{R 1}$ and $c_{\mathrm{N}_{2} \mathrm{O}}$ (see text). The solid line shows the nonlinear regression fit to the Arrhenius equation (the correlation coefficient is 0.986). The inset presents the nonlinear regression fit to eqn (7) resulting from the transition state theory.

presents the nonlinear regression fit to eqn (7), which results from the transition state theory and thus is more appropriate for comparison with our DFT computations. Fit to eqn (7) results in a slightly lower value of the activation energy, $E_{\mathrm{a}}^{\prime}=$ $(59.9 \pm 2.1) \mathrm{kJ} \mathrm{mol}^{-1}$.

$$
k_{\mathrm{R} 1}=A^{\prime} T \times \exp \left(-\frac{E_{\mathrm{a}}^{\prime}}{R T}\right)
$$

The value of $E_{\mathrm{a}}^{\prime}$ is very close to the $[\mathrm{H}-\mathrm{ONN}]^{\ddagger}$ transition state energy predicted by SMD and PCM models (see Table 4). It indicates the predominance of the direct reaction path shown in Fig. 2b, but does not exclude the indirect path through the $\mathrm{H}^{*}$ atom attachment to the $\mathrm{N}$ atom of the $\mathrm{N}_{2} \mathrm{O}$ molecule. As seen in Fig. 2a the total energy expense associated with the formation of $[\mathrm{H}-\mathrm{NNO}]^{\ddagger}$, subsequent relaxation to cis-HNNO, and transformation to $[\mathrm{NNOH}]^{\ddagger}$ is equal to the $[\mathrm{NNOH}]^{\ddagger}$ transition state energy relative to the reactants. As seen from Table 4 the energy values of $[\mathrm{NNOH}]^{\ddagger}$ in solution are only slightly higher than $E_{\mathrm{a}}^{\prime}$. Taking the PCM barrier heights of 54.2 and $67.6 \mathrm{~kJ} \mathrm{~mol}^{-1}$ corresponding to the direct and indirect paths, respectively, the value of $E_{\text {a }}^{\prime}$ can be reproduced by the weighted sum assuming $57.5 \%$ contribution of the direct mechanism. Taking the respective SMD barrier heights, 54.6 and $65.5 \mathrm{~kJ} \mathrm{~mol}^{-1}$, the contribution of the direct path is $51.2 \%$. Thus, in agreement with all the solvent models, the measured value of the activation energy indicates two mechanisms for the reaction $\mathrm{H}^{*}+\mathrm{N}_{2} \mathrm{O}$ in solution: (i) formation of $[\mathrm{H}-\mathrm{ONN}]^{\ddagger}$ directly decaying into $\mathrm{N}_{2}$ and $\mathrm{OH}$, and (ii) less contributing indirect path through the formation of $[\mathrm{H}-\mathrm{NNO}]^{*}$, relaxation to cis-HNNO, and subsequent transformation to the $[\mathrm{NNOH}]^{\ddagger}$ transition state finally decomposing to the products.

\section{Solvent effect on the reaction mechanism}

Our pulse radiolysis measurements over the temperature range of 296-346 K show that the reaction of $\mathrm{H}^{\circ}$ with $\mathrm{N}_{2} \mathrm{O}$ in solution requires almost three times higher activation energy than the reaction in the gas phase (see the first Arrhenius term in eqn (1)). Since Bozzelli et al. ${ }^{36}$ confirmed that at temperatures below $500 \mathrm{~K}$ loss of the reactants in the gas phase leads to the 
formation of $\mathrm{N}_{2}$ and ${ }^{\circ} \mathrm{OH}$, two hypothesis were considered to explain unexpectedly weak temperature dependence of the reaction rate constant. Marshall et al. suggested the $\mathrm{H}^{*}$ atom addition to the nitrogen end of the $\mathrm{N}_{2} \mathrm{O}$ molecule and the quantum mechanical tunnelling through the barrier to produce $[\mathrm{NNOH}]^{\ddagger}$ dissociating into $\mathrm{N}_{2}$ and ${ }^{\circ} \mathrm{OH} \cdot{ }^{13}$ An alternative hypothesis assumed the collisional stabilisation of the H-NNO adduct and its rapid diffusion to the wall followed by the decay into $\mathrm{N}_{2}$ and $\mathrm{OH}^{36-38}$ Whichever hypothesis is true, our pulse radiolysis measurements indicate that the suggested processes do not occur in solution. The quantum mechanical tunnelling from $[\mathrm{H}-\mathrm{NNO}]^{\star}$ to $[\mathrm{NNOH}]^{\star}$ or the collisional stabilization and decay of $[\mathrm{H}-\mathrm{NNO}]^{\ddagger}$ are probably specific for the gas phase reaction below $500 \mathrm{~K}$ since at higher temperatures the increase in the reaction rate constant is more rapid. The activation energy $62.8 \mathrm{~kJ} \mathrm{~mol}^{-1}$ observed by Hidaka et al. in shock-tube experiments over the temperature range of 1450-2200 K (ref. $39)$ is close to the value of $E_{\mathrm{a}}$ measured in solution. It may suggest that, like in aqueous solution, the reaction of the $\mathrm{H}^{*}$ atom with $\mathrm{N}_{2} \mathrm{O}$ in high temperature gases may proceed via two paths: directly through the formation of $[\mathrm{H}-\mathrm{ONN}]^{+}$or indirectly through the $\mathrm{H}^{\cdot}$ attack on the $\mathrm{N}$ atom followed by relaxation to cis-HNNO and subsequent transformation to $[\mathrm{NNOH}]^{\star}$ dissociating into $\mathrm{N}_{2}$ and ${ }^{\circ} \mathrm{OH}$.

\section{Summary and conclusion}

To the best of our knowledge, in contrast to the gas phase, the temperature dependence for the reaction $\mathrm{H}^{\cdot}+\mathrm{N}_{2} \mathrm{O} \rightarrow{ }^{\circ} \mathrm{OH}+\mathrm{N}_{2}$ has never been studied in solution. To fill this gap we have combined here pulse radiolysis kinetic measurements and DFT computations with the aim to measure the activation energy and indicate the reaction mechanism. Comparative observations of the decay of $\mathrm{Cl}_{2}{ }^{-}$- in pulse-irradiated $0.1 \mathrm{M} \mathrm{HCl}$ solution saturated with $\mathrm{N}_{2}$ and $\mathrm{N}_{2} \mathrm{O}$ showed particularly slower decay in the latter system at $7 \mathrm{~ns}$ pulse (lower dose) confirming the contribution of the $\mathrm{H}^{*}$ atom reaction with the dissolved $\mathrm{N}_{2} \mathrm{O}$. The observed slow-down was significantly enhanced by the increasing temperature. The kinetic measurements over the temperature range of 296-346 $\mathrm{K}$ and numerical simulation showed the Arrhenius dependence of the reaction rate constant with the activation energy established to be $(62.6 \pm 2.1) \mathrm{kJ}$ $\mathrm{mol}^{-1}$ or $(59.9 \pm 2.1) \mathrm{kJ} \mathrm{mol}^{-1}$ depending on a form of the preexponential factor in the Arrhenius equation, $A$ or $A^{\prime} \times T$, respectively.

The UB3LYP/cc-pVTZ computations have been performed for the reaction $\mathrm{H}^{\cdot}+\mathrm{N}_{2} \mathrm{O} \rightarrow{ }^{\circ} \mathrm{OH}+\mathrm{N}_{2}$ in vacuum and in solution using three water-solvent models: C-PCM, IEF-PCM, and SMD. We have showed that the reaction initiated by the $\mathrm{H}^{*}$ atom attack on the oxygen atom in the $\mathrm{N}_{2} \mathrm{O}$ molecule results in the formation of the $[\mathrm{H}-\mathrm{ONN}]^{\star}$ transition state directly decomposing into ${ }^{\circ} \mathrm{OH}$ and $\mathrm{N}_{2}$. According to SMD model the energy barrier associated with this direct path is $54.6 \mathrm{~kJ} \mathrm{~mol}^{-1}$ in comparison with $54.2 \mathrm{~kJ} \mathrm{~mol}^{-1}$ predicted by the PCM models and $53.0 \mathrm{~kJ} \mathrm{~mol}{ }^{-1}$ corresponding to the reaction in vacuum. Computations assuming the $\mathrm{H}^{*}$ atom attack on the $\mathrm{N}$ atom revealed the indirect reaction mechanism including the formation of $[\mathrm{H}-\mathrm{NNO}]^{\ddagger}$, the adduct decay to cis-HNNO intermediate, transformation of cis-HNNO to $[\mathrm{NNOH}]^{\ddagger}$, and decomposition to ${ }^{\circ} \mathrm{OH}$ and $\mathrm{N}_{2}$. In contrast to the direct path, the total energy expense associated with the indirect mechanism, 65.5 and $67.6 \mathrm{~kJ} \mathrm{~mol}^{-1}$ as predicted by SMD and PCM models, is slightly smaller than $67.7 \mathrm{~kJ} \mathrm{~mol}^{-1}$ computed in vacuum. The energy expense associated with the direct and indirect paths is similar and show good agreement with the activation energy obtained from the pulse radiolysis experiments. As the measured value is in-between the computed energy barriers we conclude that both mechanisms may occur in solution, but with a slight predominance of the direct one. This is in contrast to the literature reports on the gas phase reaction at temperatures below $500 \mathrm{~K}$ indicating almost three times lower activation energy and suggesting either the quantum mechanical tunnelling from $[\mathrm{H}-\mathrm{NNO}]^{*}$ to $[\mathrm{NNOH}]^{*}$ or the collisional stabilisation and decay of the $\mathrm{H}-\mathrm{NNO}$ adduct into $\mathrm{N}_{2}$ and ${ }^{\circ} \mathrm{OH}$.

\section{Acknowledgements}

The financial support from the Lodz University of Technology is greatly acknowledged. Dr Michał Rostkowski is thanked for a discussion of the DFT results obtained for the gas phase reaction.

\section{References}

1 D. S. Reay, E. A. Davidson, K. A. Smith, P. Smith, J. M. Melillo, F. Dentener and P. J. Crutzen, Nat. Clim. Change, 2012, 2, 410-416.

2 M. Dameris, Angew. Chem., Int. Ed., 2010, 49, 489-491.

3 W. C. Wang, Y. L. Yung, A. A. Lacis, T. Mo and J. E. Hansen, Science, 1976, 194, 685-690.

4 K. Severin, Chem. Soc. Rev., 2015, 44, 6375-6386.

5 D. Zuck, P. Ellis and A. Dronsfield, Educ. Chem., 2012, 26-29.

6 S. S. Emmi and E. Takács, in Radiation chemistry. From basics to applications in material and life sciences, ed. M. SpotheimMaurizot, M. Mostafavi, T. Douki and J. Belloni, EDP Sciences, 2008, vol. 6, pp. 79-95.

7 M. Ismail, H. M. Khan, M. Sayed and W. J. Cooper, Chemosphere, 2013, 93, 645-651.

8 M. Sanchez, H. Wolfger and N. Getoff, Radiat. Phys. Chem., 2002, 65, 611-620.

9 N. Liu, T. Wang, M. Zheng, J. Lei, L. Tang, G. Hu, G. Xu and M. Wu, Chem. Eng. J., 2015, 270, 66-72.

10 J. A. Miller and C. T. Bowman, Prog. Energy Combust. Sci., 1989, 15, 287-338.

11 C. P. Fenimore and G. W. Jones, J. Phys. Chem., 1959, 63, 1154-1158.

12 H. Henrici and S. H. Bauer, J. Phys. Chem., 1969, 50, 13331342.

13 P. Marshall, A. Fontijn and C. F. Melius, J. Chem. Phys., 1987, 86, 5540-5549.

14 P. Marshall, T. Ko and A. Fontijn, J. Chem. Phys., 1989, 93, 1922-1927.

15 D. L. Baulch, C. T. Bowman, C. J. Cobos, R. A. Cox, Th. Just, J. A. Kerr, M. J. Philling, D. Stocker, J. Troe, W. Tsang, 
R. W. Walker and J. Warnatz, J. Phys. Chem. Ref. Data, 2005, 34, 757-1397.

16 L. Kazmierczak, D. Swiatla-Wojcik, J. Szala-Bilnik and M. Wolszczak, Radiat. Phys. Chem., 2016, 125, 156-159.

17 G. V. Buxton and C. R. Stuart, J. Chem. Soc., Faraday Trans., 1995, 91, 279-281.

18 L. Kazmierczak, J. Szala-Bilnik, M. Wolszczak and D. SwiatlaWojcik, Radiat. Phys. Chem., 2015, 117, 7-11.

19 D. J. Adams, S. Barlow, G. V. Buxton, T. N. Malone and G. A. Salmon, J. Chem. Soc., Faraday Trans., 1995, 91, 33033305.

20 D. Swiatla-Wojcik and G. V. Buxton, Phys. Chem. Chem. Phys., 2000, 2, 5113-5119.

21 D. Swiatla-Wojcik, Nukleonika, 2008, 53, 31-37.

22 W. G. Burns, H. E. Sims and J. A. Goodall, Radiat. Phys. Chem., 1984, 23, 143-180.

23 S. Ma'mun and H. F. Svendsen, Energy Procedia, 2009, 1, 837843.

24 W. Wagner and A. Pruß, J. Phys. Chem. Ref. Data, 2002, 31, 387-535.

25 J. F. Castillo, M. A. Collins, F. J. Aoiz and L. Banares, J. Chem. Phys., 2003, 118, 7303-7312.

26 J. F. Castillo, F. J. Aoiz, L. Banares and M. A. Collins, J. Phys. Chem. A, 2004, 108, 6611-6623.

27 N. L. Haworth, J. C. Mackie and G. B. Bacsay, J. Phys. Chem. A, 2003, 107, 6792-6803.

28 S. P. Walch, J. Chem. Phys., 1993, 98, 1170-1177.

29 J. L. Durant Jr, J. Phys. Chem., 1994, 98, 518-521.

30 T. Fueno, M. Fukuda and K. Yokoyama, Chem. Phys., 1988, 124, 265-272.

31 M. J. Frisch, G. W. Trucks, H. B. Schlegel, G. E. Scuseria, M. A. Robb, J. R. Cheeseman, G. Scalmani, V. Barone, B. Mennucci, G. A. Petersson, H. Nakatsuji, M. Caricato, X. Li, H. P. Hratchian, A. F. Izmaylov, J. Bloino, G. Zheng, J. L. Sonnenberg, M. Hada, M. Ehara, K. Toyota, R. Fukuda, J. Hasegawa, M. Ishida, T. Nakajima, Y. Honda,
O. Kitao, H. Nakai, T. Vreven, J. A. Montgomery Jr, J. E. Peralta, F. Ogliaro, M. Bearpark, J. J. Heyd, E. Brothers, K. N. Kudin, V. N. Staroverov, R. Kobayashi, J. Normand, K. Raghavachari, A. Rendell, J. C. Burant, S. S. Iyengar, J. Tomasi, M. Cossi, N. Rega, J. M. Millam, M. Klene, J. E. Knox, J. B. Cross, V. Bakken, C. Adamo, J. Jaramillo, R. Gomperts, R. E. Stratmann, O. Yazyev, A. J. Austin, R. Cammi, C. Pomelli, J. W. Ochterski, R. L. Martin, K. Morokuma, V. G. Zakrzewski, G. A. Voth, P. Salvador, J. J. Dannenberg, S. Dapprich, A. D. Daniels, Ö. Farkas, J. B. Foresman, J. V. Ortiz, J. Cioslowski and D. J. Fox, Gaussian 09, Revision E.01, Gaussian, Inc., Wallingford CT, 2009.

32 R. A. Kendall, T. H. Dunning Jr and R. J. Harrison, J. Chem. Phys., 1992, 96, 6796-6806.

33 A. V. Marenich, Ch. J. Cramer and D. G. Truhlar, J. Phys. Chem. B, 2009, 113, 6378-6396.

34 J. Tomasi, B. Mennucci and E. Cancés, J. Mol. Struct.: THEOCHEM, 1999, 464, 211-226.

35 M. Cossi, N. Rega, G. Scalmani and V. Barone, J. Comput. Chem., 2003, 24, 669-681.

36 J. W. Bozzelli, A. Y. Chang and A. M. Dean, 25th Symp. (Int.) Combustion, 1994, pp. 965-974.

37 N. L. Arthur, I. A. Cooper and Y. M. Gershenzon, J. Chem. Soc., Faraday Trans., 1997, 93, 3485-3490.

38 E. W. G. Diau and M. C. Lin, J. Phys. Chem., 1995, 99, 65896594.

39 Y. Hidaka, H. Takuma and M. Suga, Bull. Chem. Soc. Jpn., 1985, 58, 2911-2916.

40 K. Takahashi, S. Ohgami, Y. Koyama, S. Sawamura, T. W. Marin, D. M. Bartels and C. D. Jonah, Chem. Phys. Lett., 2004, 383, 445-450.

41 K. Sehested and H. Christensen, Radiat. Phys. Chem., 1999, 36, 499-500.

42 J. Szala-Bilnik, P. Pierscieniewska, M. Wolszczak and D. Swiatla-Wojcik, Radiat. Phys. Chem., 2014, 97, 184-187. 